\title{
Stéphanie Caron, Réinventer le lyrisme. Le surréalisme de Joyce Mansour
}

Sara Arena

\section{(2) OpenEdition}

1 Journals

\section{Edizione digitale}

URL: http://journals.openedition.org/studifrancesi/9032

DOI: $10.4000 /$ studifrancesi.9032

ISSN: 2421-5856

\section{Editore}

Rosenberg \& Sellier

\section{Edizione cartacea}

Data di pubblicazione: 1 octobre 2008

Paginazione: 489-490

ISSN: 0039-2944

\section{Notizia bibliografica digitale}

Sara Arena, «Stéphanie Caron, Réinventer le lyrisme. Le surréalisme de Joyce Mansour», Studi Francesi [Online], 155 (LII | II) | 2008, online dal 30 novembre 2015, consultato il 13 janvier 2021. URL: http:// journals.openedition.org/studifrancesi/9032 ; DOI: https://doi.org/10.4000/studifrancesi.9032

Questo documento è stato generato automaticamente il 13 janvier 2021.

\section{(c) (i) (9)}

Studi Francesi è distribuita con Licenza Creative Commons Attribuzione - Non commerciale - Non opere derivate 4.0 Internazionale. 


\title{
Stéphanie Caron, Réinventer le lyrisme. Le surréalisme de Joyce Mansour
}

\author{
Sara Arena
}

\section{NOTIZIA}

STÉPHANIE CARON, Réinventer le lyrisme. Le surréalisme de Joyce Mansour, Genève, Droz, 2007, pp. 383.

1 Dopo che la pubblicazione, nel 2001, del volume Joyce Mansour prose et poésie, ha reso nuovamente accessibile agli studiosi una parte dell'opera della poetessa e scrittrice surrealista, dando origine negli ultimi anni a un certo numero di studi critici, questa monografia ripercorre il suo itinerario artistico alla luce in particolare delle forme che in essa assume il "soggetto lirico".

2 I testi di Joyce Mansour, che spaziano dal teatro alla poesia, alla prosa, appaiono infatti tutti accomunati dalla ricerca di un'identità che, lungi dal preesistere alla parola, proprio nella parola si crea e si compone. In questo senso, come ricerca di sé attraverso il linguaggio e immersione nelle forme più oscure dell'interiorità, la poesia può considerarsi secondo Stéphanie Caron presente in tutte le sue opere, indipendentemente dal genere, e il soggetto lirico diventa un fondamentale strumento critico per tracciarne un profilo evolutivo.

3 Le tre parti dello studio sono dedicate a ciascuno dei periodi in cui l'autrice propone di suddividere l'opera di Mansour: un primo periodo, caratterizzato dall'estrema varietà dei generi praticati e dalla costante ricerca di una visione esterna sull'io, colto in una sorta di voluta alterità attraverso un particolare utilizzo dei pronomi e una certa propensione all'estetica della «parole irréfléchie» (p. 26); una seconda fase, delineata da un'alternanza tra il romanzo e la poesia, in questo caso classicamente intesa come 
"parola in versi"; una terza fase, infine, contrassegnata dalla collaborazione sempre più frequente con artisti, scultori e fotografi e dall'abbandono della forma narrativa.

4 Nonostante il punto di vista, specifico e volutamente parziale, prescelto per indagare la poetica di Joyce Mansour, lo studio di Stéphanie Caron è anche e soprattutto una valida presentazione e introduzione al complesso dei suoi scritti, di cui finisce per tracciare una ragionata parabola cronologica. 